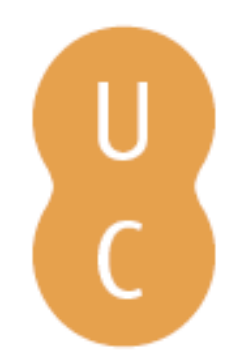

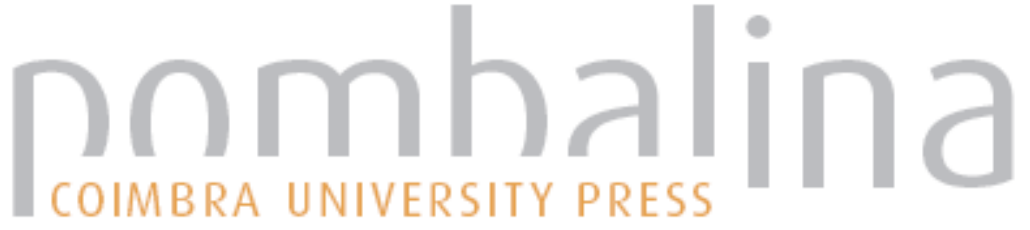

\section{História colonial: história do colonizador ou história do colonizado?}

Autor(es): $\quad$ Garcia, José Luís Lima

Publicado por: Imprensa da Universidade de Coimbra

URL

persistente:

URI:http://hdl.handle.net/10316.2/31598

DOI:

DOI:http://dx.doi.org/10.14195/978-989-26-0199-1_10

Accessed : $\quad$ 26-Apr-2023 14:17:20

A navegação consulta e descarregamento dos títulos inseridos nas Bibliotecas Digitais UC Digitalis, UC Pombalina e UC Impactum, pressupõem a aceitação plena e sem reservas dos Termos e Condições de Uso destas Bibliotecas Digitais, disponíveis em https://digitalis.uc.pt/pt-pt/termos.

Conforme exposto nos referidos Termos e Condições de Uso, o descarregamento de títulos de acesso restrito requer uma licença válida de autorização devendo o utilizador aceder ao(s) documento(s) a partir de um endereço de IP da instituição detentora da supramencionada licença.

Ao utilizador é apenas permitido o descarregamento para uso pessoal, pelo que o emprego do(s) título(s) descarregado(s) para outro fim, designadamente comercial, carece de autorização do respetivo autor ou editor da obra.

Na medida em que todas as obras da UC Digitalis se encontram protegidas pelo Código do Direito de Autor e Direitos Conexos e demais legislação aplicável, toda a cópia, parcial ou total, deste documento, nos casos em que é legalmente admitida, deverá conter ou fazer-se acompanhar por este aviso.

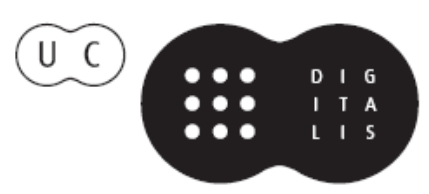


Maria Manuela Tavares Ribeiro

Coordenação

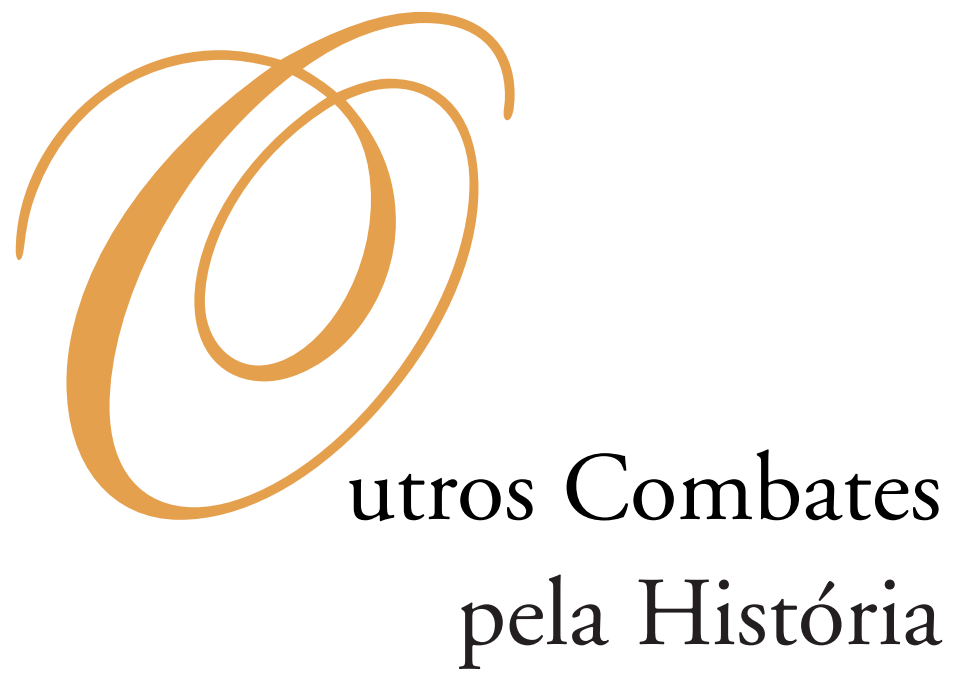




\section{COORDENAÇĀO EDITORIAL}

Imprensa da Universidade de Coimbra

Email: imprensauc@ci.uc.pt

URL: http://www.uc.pt/imprensa_uc

Vendas online: http://livrariadaimprensa.com

\section{CONCEPÇÃO GRÁFICA}

António Barros

\section{ORgANIZAÇĀO DOS TEXTOS}

Isabel Maria Luciano

Marlene Taveira

PRÉ-IMPRESSÃO

António Resende

Imprensa da Universidade de Coimbra

EXECUÇÃO GRÁFICA

SerSilito • Maia

ISBN

978-989-26-0041-3

DEPósito LEGAL

OBRA PUBLICADA COM O APOIO DE:

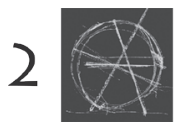

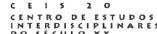

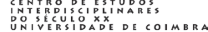

FCT Fundação para a Ciência e a Tecnologia

MINISTÉRIO DA CIÊNCIA, TECNOLOGIA E ENSINO SUPERIOR Portugal

Programa Operacional Ciência, Tecnologia, INOVAÇĀo DO QUADRo COMUNITÁRIO DE APOIO III

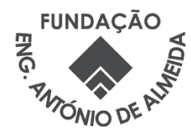

C JULHO 2010, IMPRENSA DA UNIVERSIDADE DE COIMBRA 
Maria Manuela Tavares Ribeiro

Coordenação

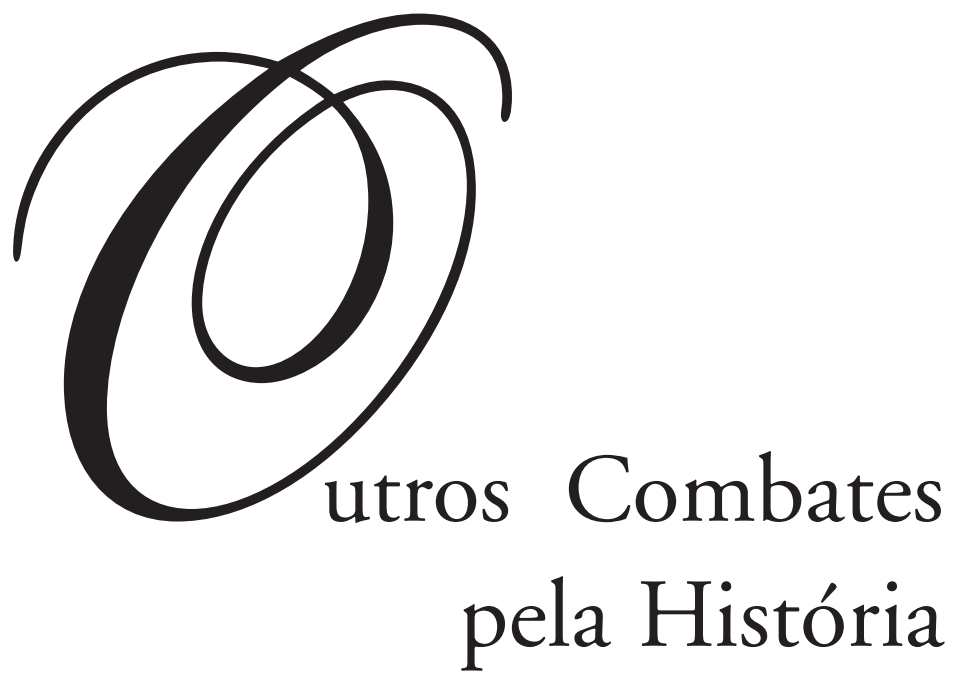

- colmbra 2010 
História e Política 
José Luís Lima Garcia

\title{
História COlonial: História do COlONIZAdor OU HistóRIA do COLONIZADO?
}

\begin{abstract}
«...Você recolhe os factos. Para isso vai aos Arquivos. Esses celeiros de factos. Lá, só tem de se baixar para os recolher. Cestadas cheias. Sacode-lhes o pó. Pousa-os na sua mesa. Faz o que fazem as crianças quando se divertem com «cubos» e trabalham para reconstituir a bela imagem que alguém decompôs para elas... A partida está jogada. A história está feita. Que quer mais? Nada. Senão: saber porquê. Porquê fazer a história? E logo, o que é a história?
\end{abstract}

Lucien Febvre, «A História Historicizante - sobre uma forma de história que não é a nossa» in Combates pela História - I, Lisboa, Editorial Presença, Biblioteca de Ciências Humanas n. ${ }^{\circ}$ 59, 1977, pp. 175-181, especialmente p. 180.

Cinquenta e seis anos depois de Lucien Febvre ter escrito estas considerações, continua a interrogação sobre "o que é a história?» Esta questão de querer saber o que é esta ciência social torna-se ainda mais pertinente quanto nos referimos à história colonial. De facto o que é esta história? Será uma história esquecida ou com interesse para as novas gerações nascidas após o processo de descolonização? Será uma história do arrependimento do ex-colonizador ou de subtil paternalismo sobre o ex-colonizado? Pejada de ambiguidades e de contradiçôes, este passado continua na actualidade, trinta e três anos após as independências lusófonas, praticamente ausente dos conteúdos científicos dos currículos das disciplinas de história das principais escolas universitárias portuguesas. Também essa memória se mantém quase esquecida nos órgãos de comunicação social que lhe deveriam devotar mais atenção e uma das poucas excepções foi a reportagem que a televisão estatal passou no final de 2007 sobre a guerra colonial, de autoria do jornalista Joaquim Furtado. Relativamente a mostras e exposiçóes sobre temática colonial, estas passaram completamente despercebidas sobre as programações dos museus portugueses e mesmo aqueles que mantêm um espólio marcadamente relacionado com esta temática, como são os museus de Etnologia e da Sociedade de Geografia de Lisboa que poderiam ter feito mais para reavivar este passado recente da história portuguesa. 
Quanto ao acervo documental espalhado por vários arquivos, convirá salientar o papel que a Fundação Portugal/África ${ }^{1}$ está a fazer desde 1997 na recuperação dessa memória colonial com a digitalização de arquivos dos Países Africanos de Língua Oficial Portuguesa (Cabo Verde, Guiné, S. Tomé e Príncipe, Angola e Moçambique) e de colecçôes de periódicos de referência como o Boletim da Agência Geral das Colónias/ Ultramar e o Boletim Cultural da Guiné. Embora tímidas estas medidas estarão certamente a contribuir para a socialização desta memória do passado recente de Portugal, de forma a dar a conhecer esse passado imperial junto daquelas gerações que ainda nasceram nos territórios coloniais sob administração das autoridades de Lisboa ou que já nasceram na antiga metrópole europeia, após o período da descolonização.

$\mathrm{Na}$ história colonial, tal como referiu Lucien Febvre, não bastava ir aos «arquivos», esses «celeiros de factos». Não chegava recolher "cestadas» de acontecimentos e «sacudir-lhes o pó». Era preciso ir mais longe, porque a história ainda não está feita e epistemologicamente procura saber o "porquê» daquela produção memorialista que se referia à dominação de Portugal sobre os territórios de Além-Mar. E nesta procura não era suficiente encetar apenas o debate ideológico sobre os aspectos positivos e negativos da colonização, pois esta era parcial, subjectiva e truncada. Como exemplo dos pressupostos aleatórios desta confrontação de ideias por vezes muito emotiva e pouco racional temos os discursos dúplices do colonizador e do colonizado: quando se fala em escolas, estradas e hospitais na perspectiva de sucesso do colonizador, está a esquecer-se que para a concretização dessas utopias se acrescentavam os aspectos negativos que se associavam aos colonizados quando construíam essas benfeitorias quer em termos do trabalho compelido e mal remunerado, quer do pouco aproveitamento que se retirava desses equipamentos, visto que a relação colonial sendo desigual iria aproveitar mais o colonizador, do que o colonizado. Portanto, mais do que a questão ideológica, a história colonial deveria ser encarada na perspectiva cientifizante de um passado memorialístico que era preciso construir com comprovação, tal como Febvre nos indicava nesse seu ensaio sobre Os Combates pela História.

Será pois neste paradigma de questionar e pensar o facto humano quando este é analisado, a verdadeira perspectiva do historiador que, mais do que o facto colonial na versão global dos seus agentes interventores (colonizadores e colonizados), pretenderá ir mais além e saber os «porquê» desta narrativa que, apesar de ter ocorrido durante toda a contemporaneidade dos séculos XIX e XX, já nesses séculos se mostrava deslocada e fora da conjuntura temporal, como qualquer outro anacronismo. Mas sendo anacrónica, a história colonial tem memória e é esse passado que para não cair no esquecimento deverá ser socializado numa nova história crítica da colonização. De facto, ao considerarmos na actualidade esse passado teremos que nos defrontar com a história do colonizador, a «nossa» história, e a história do colonizado, a história dos «outros». Esta duplicidade entre dominador e dominado fora severamente retratada por Albert Memmi quando afirmava: «nada poderia legitimar melhor os privilégios

${ }^{1}$ As principais instituições que apoiam esta fundação para a digitalização da documentação colonial existente em Portugal e nos Países de Língua Oficial Portuguesa são: Instituto de Investigação Científica e Tropical, Instituto Superior de Ciências do Trabalho e da Empresa, Instituto Superior de Economia e Gestão, em Lisboa; Universidade de Aveiro, em Aveiro. 
do colonizador que o seu trabalho; nada poderia servir melhor a decifração do colonizado que a sua ociosidade. O retrato mítico do colonizado revelará portanto uma incrível indolência; o retrato do colonizador o gosto virtuoso pela acção» ${ }^{2}$.

A exorcização destas duas "visões» inevitavelmente irredutíveis que durante o período colonial levantou ilusôes e mal-entendidos levara investigadores e a opinião pública em geral a acreditar que haveria dois estratos de memória: uma mais erudita de vestígios literários que se poderia diluir nas histórias nacionais das metrópoles; outra, oral, que emanava dos testemunhos dos actores ainda vivos da dominação colonial que se iriam dissolver na história dos Estados que se tornariam independentes. Era portanto nestas duas memórias tão recalcadas e tão idiossincraticamente nostálgicas, de administradores e nativos, que o historiador colonial deveria construir uma história isenta e limpa de qualquer prurido ideológico que pudesse advir de cada uma das partes intervenientes neste processo anacrónico de dominação.

Desta forma, a história actual do «imaginário colonial», como outrora a história da "gestão colonial», fizera-se sempre na metrópole e aí nesse local, mesmo depois das independências continuava a ser o centro de todo um património memorialístico de muitos séculos que contemplava o passado dos antigos colonizadores e colonizados. Gerir esse património implicava compreender as nostalgias de uns sobre o «eldorado» da sua dominação, mas também atender às queixas e aos pedidos de reparação de outros, sobretudo daqueles que se sentiram explorados nas suas próprias terras. Assim, o historiador colonial deverá saber defender-se do "chauvinismo" epistemológico deste tipo de história fechada, autista e plena de complexos de superioridade cultural. Em contrapartida, terá que partir para uma outra visão historiográfica em que o paradigma do outro se sobreponha ao do «nós» do antigo colonizador, para deste modo poder compreender e interpretar melhor o "facto colonial» não à luz do antigo narcisismo etnocêntrico, mas sim com a clareza e o sentido crítico do investigador que trabalhando sobre os «factos» os vai interpelar, associar e experimentar para construir o seu próprio objecto de ciência. Tal como afirmava Lucien Febvre, na interpretação é que estava a verdadeira leitura desses "cortes» factuais e nessa tarefa o historiador deveria proceder com cuidado "porque descrever o que se vê, ainda passa, mas ver o que se deve descrever, isso é que é terrível!»33

Mas para fazer a análise desses factos que ocorreram durante o longo período da colonização que vai da época Moderna à Contemporânea é necessário que o historiador não esqueça o conteúdo desse meio milénio de acontecimentos relevantes para a história da Humanidade. Por que razão este período se encontra então tal mal estudado? Como compreender este desinteresse de pesquisa e inventariação, quando na verdade os estudos e as abordagens científicas evoluíram, permitindo fazer uma investigação mais segura e isenta, livre de preconceitos raciais e complexos de culpa? Apesar do desinteresse, de alguma subalternidade e do preconceito ideológico, as investigações sobre o passado colonial depois do 25 de Abril de 1974 e do período que se seguiu ao processo de descolonização em 1975 continuaram a ser feitas, algumas ainda

2 Albert Memmi, «Retrato Mítico do Colonizador - Nascimento do mito" in Retrato do Colonizado precedido do Retrato do Colonizador, Lisboa, Mondar Editores, 1974, pp. 119-130, especialmente p. 119.

3 Lucien Febvre, "A História Historicizante ...», op. cit., p. 178. 
utilizando a abordagem clássica de uma história hagiográfica centrada no culto do herói e nos valores etnocêntricos do português colonizador, muito embora nos últimos anos, nomeadamente a partir da década de noventa, do século XX, tenham aparecido novos trabalhos de carácter sócio-histórico de uma geração de investigadores que já nasceram após a independência desses territórios ou que embora tenham nascido nos trópicos vieram crianças para a Europa, não retendo na memória qualquer remorso ou acto de culpa que costuma estar associado à idiossincrasia do imaginário colectivo do antigo colonizador.

Desta forma esses estudos têm-se centrado na abordagem de certos aspectos da colonização, nomeadamente das nuances que a mesma tomou no período contemporâneo com os regimes republicanos europeus, incluindo o português. Em França, por exemplo publicara-se em 2003 um livro sobre La République Coloniale - Essai sur une Utopie 4 , precursor desta interpretação do facto colonial associado a um regime que em princípio deveria ter tomado um outro tipo de atitude que não a de dominação face aos seus territórios ultramarinos. A propósito desta interpretação historiográfica os autores do livro, Françoise Vergés, Nicolas Bancel e Pascal Blanchard, confrontavam o regime republicano francês com o seu império, afirmando o seguinte: "para a grande maioria dos intelectuais, a colonização aparecia como um epifenómeno - por vezes digno de uma nota de fim de página ou de um subcapítulo numa obra colectiva -, uma empresa longínqua, pintada de exotismo ou de rapacidade segundo as aproximaçôes, mas em todo o caso exterior à história de França... A dificuldade em regressar a estas páginas de história tinha, em grande parte, aquilo que se chama de compromisso da República na expansão colonial, com o perigo da hesitação desses valores. Estas violações dos princípios republicanos justificam-se pelo preço de uma marginalização dos crimes cometidos sob os regimes republicanos, de uma impossibilidade em os considerar por aquilo que eles foram: crimes não iguais, mas comparáveis aqueles que foram reconhecidos como a expressão do horror em si mesmo, os crimes do regime nazi» 5 .

Mas estes estudos ainda abordaram outros aspectos da história da colonização relacionados com a análise a certas instituiçôes de domínio e influência sobre os territórios ultramarinos como a administração, a arquitectura e a urbanização, a diplomacia, a educação, o exército, a justiça, o mundo laboral, a saúde. Tal como referia Claude Liauzu ${ }^{6}$, esta historiografia tinha o direito de fazer o «inventário da colonização", para desta forma, nas palavras de Achille Mbembe, mostrar que a colonização não tinha sido a única via possível da modernidade no Mundo, tal como o Ocidente não tinha sido o único modelo e a única matriz e que havia outras vias que alternavam com uma "Europa que havia excluído os colonizados da história, as pessoas não ocidentais da individualidade, as sociedades diferentes da modernidade». Daniel Rivet, professor de história contemporânea na Sorbonne, escrevera a propósito um livro sobre Le Maghreb à l'Épreuve de la Colonisation ${ }^{7}$ onde procurava com o

\footnotetext{
${ }^{4}$ Françoise Vergés, Nicolas Bancel e Pascal Blanchard, La République Coloniale - Essai sur une Utopie, Paris, Éditions Albin Michel, 2003, 172 pp.

5 Idem, «La République Coloniale: Une Crise de l' Histoire, Ibidem, pp. 21-27, especialmente p. 23.

${ }^{6}$ Claude Liauzu, Colonisation: droit d'inventaire, Paris, Armand Colin, 2004, pp. 3-10.

7 Daniel Rivet, Le Maghreb à l' Épreuve de la Colonisation, Paris, Hachette Littératures, Histoire Pluriel, 2002, 459 pp.
} 
rigor metodológico do historiador traçar o que fora a sociedade marroquina durante o período em que esteve dominada pela colonização francesa.

Desta forma procurava que sua função de escrever a história do Maghreb não fosse feita pela «hora francesa» tal como alguém que «instruísse um processo». Com este aviso à "navegação", Rivet tentava com a sua investigação "não inculpar ou desculpar nem os colonos, nem os colonizados», para que nesta dialéctica global de análise dúplice a sua perspectiva não coincidisse exactamente com o binómio "patrôes e serviçais» e muito menos com o tríptico "vencedores, vencidos e vítimas». Assim, para este especialista da África do Norte, o historiador teria «...por objectivo fazer compreender, isto é ajudar os seus contemporâneos a utilizar os olhos para serem mais perspicazes» ${ }^{8}$ na interpretação da complexidade do facto histórico, neste caso da relação colonial entre franceses e os territórios sob sua dominação em toda a região do Maghreb (Argélia, Marrocos e Tunísia).

No caso português, uma das investigações pioneiras sobre o colonialismo em África despojada desta perspectiva luso-cêntrica que caracterizaria todo o século XX e que vinha já desde o final da Monarquia, mas que tivera o seu ponto alto com o Estado Novo, era um livro de Eduardo Sousa Ferreira publicado em $1977^{9}$, mas que resultara de um estudo encomendado pela UNESCO àquele investigador e divulgado em 1974 , seis meses depois do "25 de Abril», em que se mostrava à opinião pública internacional, num momento em que Portugal estava diplomaticamente isolado e havia mesmo abandonado esse organismo para a educação, ciência e cultura das Nações Unidas, no final do ano de 1972, as principais instituiçôes sociais das colónias de África que uns meses depois reclamariam as suas independências. $\mathrm{O}$ estudo foi realizado fora de Portugal já que o investigador não tivera autorização para frequentar os arquivos e bibliotecas da metrópole e das colónias. Por isso, Sousa Ferreira tivera que se basear em fontes primárias existentes no exterior, mas em grande parte «desactualizadas», «inexactas» e «incompletas». Para colmatar esse vazio, o investigador ao serviço da UNESCO tivera que se socorrer de fontes secundárias, como livros, jornais e revistas, existentes nas principais bibliotecas da Europa e América ${ }^{10}$.

Anos mais tarde, num curso de férias coordenado por Valentim Alexandre, nome de referência no estudo do colonialismo português, organizado pelo Instituto de História Contemporânea da Faculdade de Ciências Sociais e Humanas da Universidade Nova de Lisboa, em Setembro de 1999, subordinado ao tema «O Império Africano — Séculos XIX e XX»" ${ }^{11}$, este investigador explicava no "prefácio» das actas a razão pela qual a investigação sobre este ramo da história se encontrava tão atrasado em Portugal. Uma das razões primordiais para este atraso ficava a dever-se, segundo Alexandre, ao

\footnotetext{
${ }^{8}$ Idem, Daniel Rivet, «Introduction», p. 9.

${ }^{9}$ Eduardo de Sousa Ferreira, O Fim de uma Era: O Colonialismo Português em África, Lisboa, Livraria Sá da Costa, 215 pp.

${ }^{10}$ As principais bibliotecas na Europa e América onde Eduardo de Sousa Ferreira realizou este relatório para a UNESCO eram as seguintes: Instituto Escandinavo de Estudos Africanos, Instituto Arnold Bergstrasser de Friburg, Biblioteca das Nações Unidas e Centro de Estudos Africanos de Los Angeles, na Califórnia.

${ }^{11}$ Valentim Alexandre (Coordenação), O Império Africano - Séculos XIX e XX, Lisboa, Edições Colibri, 2000, 195 pp.
} 
peso da «ideologia» que durante décadas condicionou a opinião pública com a ideia de que Portugal cumpria no Mundo uma «missão civilizadora» de instruir, educar e evangelizar as populaçôes nativas dos territórios que administrava em África e na Ásia. Mas o investigador acrescentava outros motivos a este desinteresse por temática tão rica e pertinente da história nacional: "para além do carácter envolvente dos mitos, outras dificuldades se acrescentaram à pesquisa histórica, já depois da queda do Estado Novo e da descolonização. Entre elas, as que contribuíram para afastar os jovens investigadores desta temática: a falta de apoios institucionais, motivada pela natural crise dos organismos e centros a ela dedicados, ligados ao antigo regime, que nada veio substituir; a desorganização dos arquivos, em especial do Arquivo Histórico Ultramarino, que desencorajava (e, é penoso dizê-lo, continua a desencorajar) quem quer que se propusesse fazer uma abordagem sistemática, em prazos fixados de antemão, como era o caso dos assistentes universitários. A tudo se juntou uma perspectiva exclusivamente eurocêntrica do país que, por contraponto à visão imperial anterior, se impôs nos anos seguintes à revolução de 1974 - e que teve a sua mais evidente expressão na História de Portugal coordenada pelo professor José Mattoso, onde a realidade colonial está reduzida a quase nada» 12 .

Felizmente que estes trabalhos precursores tiveram continuidade nas décadas posteriores com o aparecimento de uma nova geração de investigadores dos quais destacaremos, entre muitos, dois deles cujos trabalhos académicos foram premiados pela Universidade do Minho, em 1997 e 2005, com o prémio de «História Contemporânea para Jovens Investigadores»: um deles, Cláudia Castelo, na década de noventa, com uma investigação para uma tese de mestrado defendida em 1997, na Universidade Nova de Lisboa, sobre o «luso-tropicalismo e a ideologia colonial portuguesa, entre os anos de 1933 e $1961{ }^{13}$.

Trata-se portanto de um trabalho inovador e científico sobre uma corrente ideológica importada do Brasil, nomeadamente das interpretações sociológicas de Gilberto Freyre, que a partir de 1953 se tornou ideologia oficial, qual «modo português de estar no Mundo» a condicionar a opinião pública para a falsa ideia de que os naturais dos territórios coloniais de África e da Ásia teriam os mesmos direitos cívicos dos que os do Minho ou do Algarve, pelo que perante este axioma ideológico o alistamento militar para ir combater em defesa dessas parcelas tropicais era uma obrigação moral e um dever patriótico. Mas como afirmava Valentim Alexandre, orientador desta tese, o luso-tropicalismo não foi só um «instrumento" do governo e dos «meios oficiais» do regime estadonovista, e essa vertente mais abrangente foi também investigada por Cláudia Castelo acabando por envolver outros sectores que não o político, como o dos cientistas sociais e a restante elite que renovaram «...o enraizamento da imagem que o país constituía de si próprio como nação de vocação colonial ou, em versão mais recente, de vocação ecuménica» ${ }^{14}$.

12 Idem, Valentim Alexandre, "Prefácio», Ibidem, p. 7.

13 Cláudia Castelo, "O Modo Português de Estar no Mundo - O luso-tropicalismo e a ideologia colonial portuguesa (1933-1961)», Porto, Edições Afrontamento, Biblioteca das Ciências do Homem n. ${ }^{\circ}$ 19, 1998, $166 \mathrm{pp}$.

${ }^{14}$ Valentim Alexandre, «Prefácio», Ibidem, p. 6. 
A outra investigação pioneira de um assunto ignorado ou falseado durante o Estado Novo era a questão racial. Em 2004, uma antropóloga proveniente da Universidade de Coimbra realizaria num mestrado do Instituto de Ciências Sociais, da Universidade de Lisboa, uma investigação sobre as «representações raciais no Império Colonial Português» ${ }^{15}$. Nessa abordagem, Patrícia Ferraz de Matos analisaria uma questão pertinente que Albert Memmi considerava o «racismo do colonizado», ao contrário do racismo do colonizador, uma discriminação que não era "biológica», nem "metafísica», mas «social» e "histórica» ${ }^{16}$. E, num contexto do passado colonial, a jovem investigadora analisava as "Cores do Império" numa perspectiva triádica assente em três momentos determinantes: o percurso e a ideia histórica de «raça»; as representações dominantes sobre as populaçôes das antigas colónias a partir dos discursos, imagens e saberes; o papel das exposições coloniais, entre 1924 e 1940, na construção da imagem das populações ultramarinas. Na introdução da tese, a própria autora definia o que pretendia com esta pesquisa sobre uma temática prenhe de preconceitos ideológicos: «em Portugal só muito recentemente se assistiu à produção de trabalhos científicos sobre o racismo, de que são exemplo as recentes publicações organizadas por Jorge Vala ${ }^{17}$, que denunciam o «racismo subtil» dos portugueses. Porém, a nível nacional há ainda uma parca investigação no que diz respeito às representações raciais e, especificamente, às produzidas no âmbito do contexto do «império colonial português»" ${ }^{18}$.

Em conclusão, poderemos afirmar que após trinta e três anos sobre a data do desaparecimento deste Império a problemática desta dominação ainda não foi considerada como tema de uma reflexão metodológica entre os profissionais deste ofício de projectar o futuro, a partir da análise do passado. E a prova desse facto é o que acontece com a Universidade em que agora estamos a assinalar os dez anos de um dos seus mais reputados centros de investigação. Sendo a instituição de ensino superior das mais antigas da Europa, que acompanhou a formação de colonizadores e colonizados durante os vários séculos que durou a vigência da dominação imperial, que formou elites de portugueses para a Índia, para o Brasil, e depois, a partir do século XX, para as colónias de África, que recebeu estudantes da minoria de colonizados dessas possessões (africanas, americanas e asiáticas), que recebe ainda hoje centenas de alunos de países integrados nos Países Africanos de Expressão Oficial Portuguesa, não tenha, à semelhança de universidades com menos tradição no relacionamento com os estudantes do ex-Império, como é o caso das Universidades de Lisboa, Porto e Évora, um Centro de Estudos Tropicais que faça a ponte entre os cientistas sociais desses territórios e os portugueses, entre a história da colonização europeia e a história colonial

15 Patrícia Ferraz de Matos, As Cores do Império - Representações Raciais no Império Colonial Português, Lisboa, Imprensa de Ciências Sociais, Colecção "Estudos e Investigações» n. o 41, 2006, 287 pp.

${ }^{16}$ Albert Memmi, «As duas respostas do colonizado ", op. cit., pp. 163-186, especialmente p. 176

17 Jorge Vala, Rodrigo Brito e Diniz Lopes, Expressóes dos racismos em Portugal, Lisboa, Imprensa de Ciências Sociais, 1999, 216 pp.

18 Patrícia Ferraz de Matos, "Introdução», in As Cores do Império - Representaçôes..., pp. 17-22, especialmente p. 17. 
de África (Angola, Cabo Verde, Guiné, S. Tomé e Príncipe e Moçambique), da América (Brasil), da Ásia (China e Índia) e da Oceânia (Timor).

Percepcionamos que o Encontro Internacional realizado pelo Centro de Estudos Interdisciplinares do Século XX durante a X Semana Cultural da Universidade de Coimbra, em Fevereiro de 2008, sobre "Nação e Nacionalismos em África», poderá ser o ponto de partida para um futuro Centro que faça a ligação entre os novos territórios e a antiga metrópole, entre os ex-colonizados e o ex-colonizadores, entre a Europa e os outros Continentes, para continuar a discutir, investigar e esclarecer um passado comum, assente nos pressupostos jurídico-político e sociocultural do que foi o universo colonial, para num contexto multicultural hodierno reforçar a História de Portugal e a desses países independentes que um dia sofreram a dominação e a influência da matriz lusófona deste antigo colonizador europeu. 

Série

Documentos

Imprensa da Universidade de Coimbra

Coimbra University Press

2010

- U

C • 